\title{
Study of the influence of technical and operational indicators on the efficiency of road transport in intercity traffic
}

\author{
Irina Pogulyaeva, Irina Teterina*, and Igor Pogulyaev \\ Siberian State Automobile and Highway University (SibADI), 644089, Omsk, Mira Ave., 5 Russia
}

\begin{abstract}
The material is a study aimed at determining the relationship between technical and operational indicators and factors reflecting the efficiency of freight road transport in intercity traffic. The graphical dependencies reflecting the influence of such technical and operational indicators as speed and lifting capacity, operating time and productivity are presented (which can be expressed in both tonnes and tonne-kilometers). A scheme of a pendulum route with a return run without cargo on board has been developed. The method of calculating the operating time and productivity of freight road transport in intercity traffic is presented.
\end{abstract}

\section{Introduction}

Intercity freight traffic is an important factor in the development of the country's economy, ensuring its internal and external economic ties. Due to the size of the territory of Russia, special attention is paid to this factor [1]. Complementary elements such as process organization, process technology and process control affect the efficiency of long-distance freight services. The current economic situation in the country forced many manufacturers to concentrate on identifying such technical and operational indicators that to a greater extent determine the effectiveness of organizing intercity transportation. Purpose of the work: to determine the degree of influence of technical and operational indicators on the factors that determine the efficiency of freight road transport in intercity traffic.

\section{Researching}

To study the impact of technical and operational indicators, you can consider a specific example. Figure 1 shows a design scheme that reflects the conditions of the study. During the study, a variant of a pendulum route with a return run without cargo on board was considered [2].

\footnotetext{
*Corresponding author: iateterina@mail.ru
} 


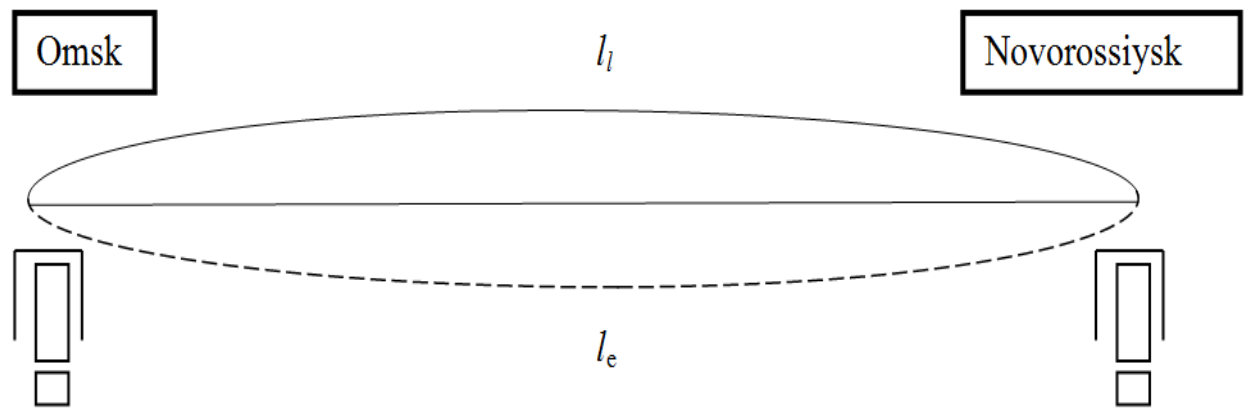

Fig. 1. Scheme of a pendulum route with a return run without cargo on board.

The studies were carried out for a model of traffic in intercity traffic according to the "just in time" system for one of the largest producers of the alcoholic industry in the Siberian Federal District. Initial conditions for research:

1. 07:00 - arrival at the warehouse;

2. Loading the car - 3 hours, manually.

3. Travel time -3 days.

4. Loading in the port - from 18.00 to 22.00 hours.

5. Travel time - 3 days.

6. An empty car is returned back.

7. Drivers work scheme - round driving.

Within the framework of this study, the following factors were chosen as the factors of the efficiency of the system: operating time per revolution in days $\left(t_{c}\right)$; truck performance in tonne-kilometers $\left(Q_{t k m}\right)$; vehicle performance in tonnes $\left(Q_{t}\right)$.

A feature of intercity transportation is the round trip time, since the working time is regulated by the "Regulations on the modes of work and rest of drivers"[3]. Another important factor characterizing the use of a fleet of trucks is transport work, which is the ratio of cargo turnover to the carrying capacity of the fleet of vehicles and shows how many ton-kilometers have been made per unit of carrying capacity. Consequently, the productivity of the vehicle fleet is formed under the influence of changes in two factors: the volume of transport work and the carrying capacity of the vehicle fleet [4].

Delivery times are primarily related to the technical or design speed at which the given transport is oriented. The delivery time depends on the type of communication, transport technologies, design features of vehicles, conditions of the transport process, including climatic and many other factors. Delivery time is based on average travel speed [5].

Based on the design scheme, the main technical and operational parameters were determined. Technical and operational indicators considered during the study: loading and unloading time; travel speed; lifting capacity of one machine; coefficient carrying capacity (vehicle loading indicator); operating time of the machine per day; mileage utilization factor $[6,7]$.

Table 1 presents the main technical and operational indicators applicable to the specific investigated situation.

Table 1. Technical and operational indicators.

\begin{tabular}{|c|c|c|c|c|c|}
\hline $\boldsymbol{t}_{\boldsymbol{l u}}, \mathbf{h}$ & $\boldsymbol{S}_{\boldsymbol{t}}, \mathbf{k m} / \mathbf{h}$ & $\boldsymbol{q}, \mathbf{t o n s}$ & $\boldsymbol{\gamma}$ & $\boldsymbol{t}_{\boldsymbol{m w}}, \mathbf{h}$ & $\boldsymbol{B}_{\boldsymbol{r}}$ \\
\hline 3 & 70 & 20 & 0.9 & 16 & 0.5 \\
\hline
\end{tabular}

Besides, it is necessary to determine the length of the route. The length of the entire route is the sum of the forward and reverse steps and is expressed in the formula 


$$
l_{m}=l_{l}+l_{e}
$$

where $l_{l}$ - is the length of the loaded flight; $l_{e}-$ length of the idle flight.

Cargo delivery distances are shown in Table 2.

Table 2. Route length.

\begin{tabular}{|c|c|}
\hline $\boldsymbol{l}_{\boldsymbol{l}} \mathbf{\text { km }}$ & $\boldsymbol{l}_{\boldsymbol{e}}, \mathbf{k m}$ \\
\hline 3474 & 3474 \\
\hline
\end{tabular}

Vehicle performance can be expressed in tons, and then the general formula for determining the performance of rolling stock is as follows.

$$
Q_{t}=\frac{q \cdot \gamma \cdot S_{t} \cdot \beta_{r}}{l_{m}+t_{l u} \cdot S_{t} \cdot \beta_{r}}
$$

where loading and unloading time $-t_{l u}, \mathrm{~h}$; travel speed $-S_{t}, \mathrm{~km} / \mathrm{h}$; lifting capacity of one machine $-q$, tonnes; coefficient carrying capacity $-\gamma$ (vehicle loading indicator); operating time of the machine per day $-t_{m w}$, h (14 hours, since at the standard one driver has seven hours of work, in this example two drivers carry the load); mileage utilization factor $-\beta_{r}$ (in this case, the coefficient is 0.5 , since the transport is returned without cargo, that is, empty) $l_{m}$ - the length of the covered route.

Alternatively, vehicle performance can be expressed in terms of ton-kilometers. Then the general formula will look like this [8]

$$
Q_{t k m}=\frac{q \cdot \gamma \cdot V_{t} \cdot \beta_{r} \cdot l_{m}}{l_{m}+t_{l u} \cdot S_{t} \cdot \beta_{r}} .
$$

The round trip time $\left(t_{0}\right)$ can be found by the formula, $\mathrm{h}$ :

$$
t_{0}=\frac{l_{\mathrm{M}}}{s_{t}}+t_{l u}
$$

The round trip time $\left(t_{c}\right)$, can be found by the formula, h:

$$
t_{c}=\frac{t_{0}}{t_{m w}}
$$

where $t_{m w}$ - vehicle operating time per day.

The total number of riders $\left(Z_{e}\right)$ is found by the formula

$$
Z_{e}=\frac{Q}{q \gamma},
$$

where $Q$ - total weight of the product; $q$ - carrying capacity of the vehicle; $\gamma$ - coefficient of relative carrying capacity.

When conducting research on changes in technical and operational indicators and their impact on the efficiency of a truck on an intercity route, the method of chain substitutions was used $[9,10]$. At the same time, one of the indicators was taken as an independent variable. The rest of the technical and operational indicators were recorded $[3,11]$.

This paper provides examples of studying the influence of such technical and operational parameters as the average speed of a truck and the carrying capacity of the vehicle. In addition, their degree of influence of indicators on the round trip time and productivity of freight road transport was investigated $[6,12]$.

Figures 2, 3, 4 show the calculated dependences of round trip time and productivity on such an indicator as speed. 


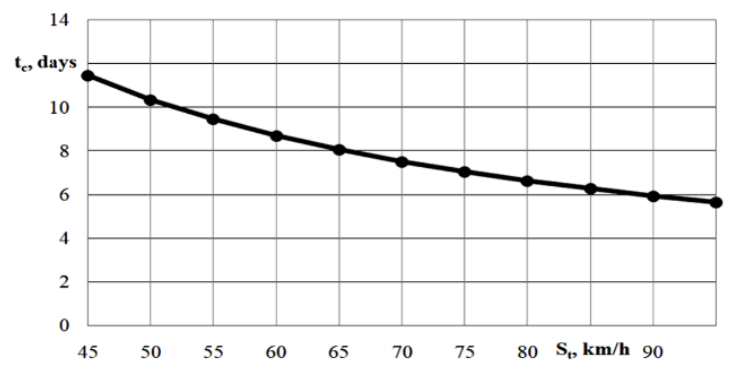

Fig. 2. Dependence of the round trip time in days on the change in vehicle speed.

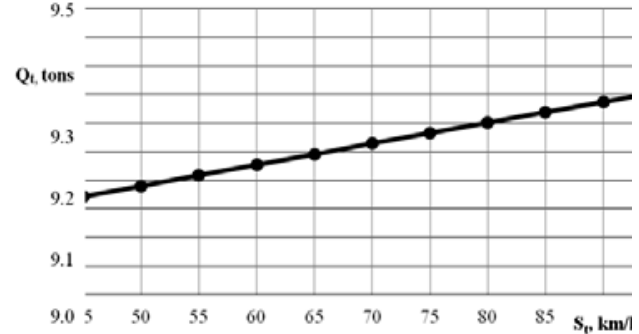

Fig. 3. Dependence of performance on changes in vehicle speed.

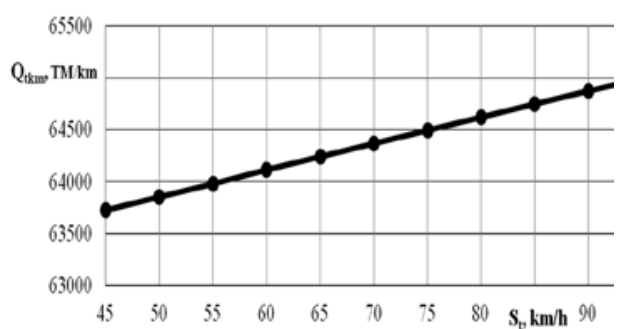

Fig. 4. Dependence of transport work on changes in vehicle speed.

Figures 5, 6 show the calculated dependences reflecting the influence of the carrying capacity of a truck on its performance [13].

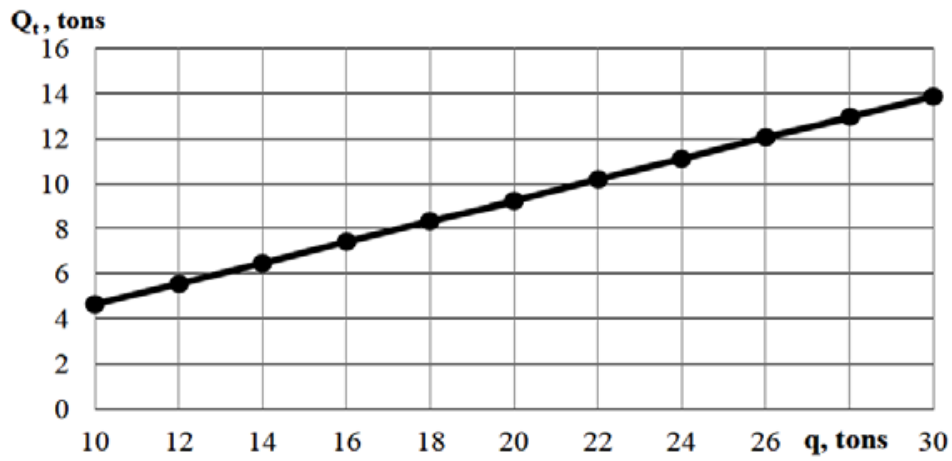

Fig. 5. Dependence of performance on vehicle carrying capacity. 


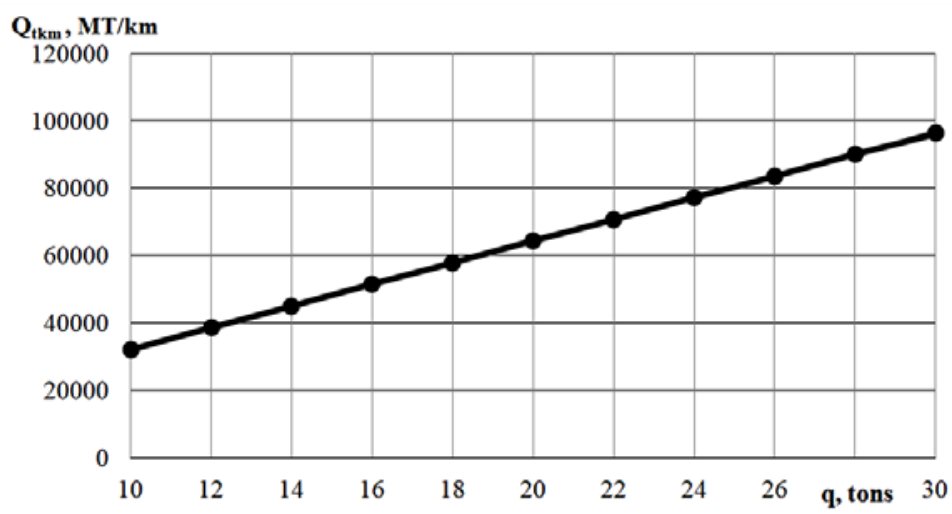

Fig. 6. Dependence of transport work on the carrying capacity of the vehicle.

\section{Research results}

According to the calculations, it can be concluded that with an increase in the average technical speed of the vehicle, the delivery time of the cargo decreases. Unlike urban transport, with intercity traffic, the number of riders does not change when the speed changes. Speed in this case only affects such indicators as the number of hours, days of delivery, as well as the increase in the number of tons per kilometer [4, 13].

The annual output depends on the number of days of operation of the first vehicle and the daily output, which, in turn, is formed under the influence of the average daily mileage, the utilization rate of the mileage, carrying capacity, and the utilization rate of the carrying capacity.

Graphical dependencies (Figure 5,6) allow us to note the following regularity - with a decrease in carrying capacity, the number of rides increases $[6,14,15]$. From Figure 6 , we can conclude that cargo turnover increases with an increase in vehicle capacity. Its value depends on the average annual number of machines and the annual output of one machine.

\section{Conclusion}

In market conditions, delivery times are of particular importance. The client usually requires delivery of certain goods "just in time", and the shipper seeks to reduce the travel time. In any situation, it is necessary not only to focus on the average delivery time, but to calculate the specific time of delivery of the goods along this route, taking into account the requirements of the cargo owner.

Delivery times can be more important than the cost of transportation, and violation of them is fraught with losses of material resources and market position for cargo owners. Generally, in the marketplace, a reasonable compromise is required between cost and urgency.

Changes in each of these indicators in one way or another affect the overall efficiency of cargo delivery, as well as its economic efficiency. At the same time, high-quality delivery of goods in full and on time increases competitiveness. 


\section{References}

1. N. G. Gavrilenko, S. A. Borodulina, A systematic approach to the strategic development of the RF motor transport system, Transport business in Russia, v. 3, pp. 100-103 (2020)

2. L. S. Trofimova, S. A. Borodulina, Modeling the demand for road transport of goods, Irkutsk State Technical University Bulletin, chapter 21, v. 10 (129), pp. 195-205 (2017)

3. D. Waters Logistics Supply Chain Management (Moscow: Uniti-Dana, 2009) p. 503

4. V. I. Burakov, Prospects for the development of logistics technologies in industrial, commercial and foreign economic activity, Electronic scientific journal "Izvestia" of the Irkutsk State Economic Academy. v. 3 p. 74 (2012)

5. B. A. Anikin Logistics (Moscow: Infra, 2000) p 598

6. I. V. Pogulyaeva, I. A. Pogulyaev, Indicators affecting the economic efficiency of road transport in intercity traffic, Internet journal Science Studies, chapter 8, v. 3 (34), p. 69, Moscow Science of Science, (2016)

7. A. M. Golubchik Transport and forwarding business: creation, formation, management (Moscow: TransLit, 200) p 317

8. B. I. Gerasimov, V. V. Zharikov, V. D. Zharikov, Basics of logistics (Moscow: Infra, 2010) p. 304

9. V. V. Varakin, E. O. Chebakova, Method of the analysis of efficiency of the organizations of freight motor transport, Transport business of Russia v. 6, pp 125-127 (2011)

10. E. R. Aitbagina, E. E. Vitvitsky, Method of two-factor analysis of cars operation in the road transport system of cargo transportation, Advances in Intelligent Systems and Computing, v. 1116, pp. 968-974 (2020)

11. S.A. Borodulina, Methodology for Process Management of Road Transport Enterprise under Conditions of a Non-Stationary Development, (Sankt-Petersburg: Publishing house of the St. Petersburg State Engineering and Economic University) p 392012 (2012)

12. S. M. Mochalin, Operational management of transport logistics of the company cargo flows, Conf: Fundamental science and technology - promising developments, USA: North Charleston, v. 2, pp. 137-139 (2015)

13. Y. A. Shcherbanin, Transport and transport infrastructure in 2030: some predictive estimates, Studies on Russian economic development, Sankt-Petersburg: Economic revival of Russia, chapter 24, v. 3, pp. 259-264 (2013)

14. H. Werner, Supply Chain Management: Grundlagen, Strategien, Instrumente und Controlling, (Wiesbaden. Springer-Verlag) p. 502 (2013)

15. I. A. Teterina, Features of small and medium entrepreneurship in Omsk region, Bulletin of the Siberian State Automobile and Highway Academy, (Omsk: SibADI), v. 6 (34), pp. 161-165 (2013) 